\title{
Teaching Literature through Multimedia: A Comparison of Maitree Express with the Novel the Shadow Lines
}

\author{
Tuhina Bose \\ Fr. C. Rodriguez Institute of Technology, Vashi, Mumbai University, India
}

\begin{abstract}
While most of the world today, is struggling with the various problems of immigration, terrorism, racism .... a part of it is trying very hard to reconcile with the inherent differences between human evolution. With the proximity and commonality that digital and media resources have facilitated, the world has shrunk and become accessible from any part. The last few decades have seen a paradigm shift in the methods of imparting education and use of technology to make learning more tangible. In this transitional phase the major shift in education has been, to try and use these facilities for better understanding of different cultures, artwork, music, literature and science.

My paper explores the possibility of making use of the multimedia technology in discovering ways and means to bring the learners closer to the text they read. I have taken the example of the postcolonial diasporic author Amitav Ghosh to extend my findings and opinions to the audience. Teaching the works of writers such as Amitav Ghosh and many others like Salman Rushdie, Jhumpa Lahiri, Naipaul, to name a few, has become more achievable and enjoyable because the use of media simulates a quasi-environment rendering the writer's perspective and image to the reader. Not just the character growth but the entire backdrops of many of their works are built up to reflect a struggle during transition from the discrete to the global; and, what could be better than to address their works through visual and auditory media, that can transform the written word into a relatable experience?
\end{abstract}

The works of such writers as Ghosh, attempt to infuse the reader with thoughts of an emerging colonial people who, through the trauma and joy of living in hardship, have discovered the power of expression in social media and pop culture. Movies like, Salaam Bombay, Namaste London, Swades, Monsoon Wedding etc. are some movies that rewrite the past and reflect the present. Such fiction and movies are now poised to slowly start influencing the global perspectives. For generations the effects of colonization like the stereotyping of the Indian masculanity as being lazy, indulgent and lusty or that of Indian culture as that of pagans with nothing to takeaway, would be endured by the people of the colonized nations.

Using multimedia for teaching allows a teacher to establish an immediate connect with her learners. Alluding to the visuals, movie depiction of a novel or a documentary, can bring alive the sentiments the writer has juggled within the narrative, especially if it is as subtle as the identity crisis!

In this context my paper argues that since the learners are often unaware of the cultural context in which a story was woven, a movie depiction can bring them closer to the real life experience and increase the sensitisation of the theme. I make a comparison of The Shadow Lines, the much appreciated and acclaimed novel of the writer Amitav Ghosh, with the BBC documentary Frontier Railways, to assert this hypothesis.

Keywords: nostalgia, multimedia, identity

\section{Introduction}

Freedom from political colonialism came as a refreshing breeze to the Indian writers who tried to connect the scattered fragmented material through their writings and thus give some meaning to it, by imposing a kind of 
order. The sense that, a narrative restores the past, is a given, and is enliven through many of the works of writers such as Salman Rushdie, Vikram Seth, Amitav Ghosh and many more. Writing with great dynamism, distinctive voice, vigour and a level of self-reliance, these writers have liberated Indian English literature from the colonial yoke and expressed their indigenous ethos and beliefs, in conjectures of Post-colonial Indian English writings. 'Historical nationalist issues such as diaspora, migration, refugees, colonial hegemony; socioeconomic and cultural issues like east-west encounter, caste and class etc. become the concerns of these writers.' [5]. One such area in the field of diasporic literature is Transnationalism, the seeds of which have been sowed in the journeys so often depicted in the narratives of these writers. Considering the historiography that these narratives address, there is a large indication that, the ethos of identity, belongingness and a borderless world is the new age reality. The generation of the present day wants to break off the shackles of nationhood, caste, creed and racism. Voicing the same concerns this paper discusses the concerns of nostalgia and belongingness in a comparison of "The Shadow Lines and India's Frontier Railways, Maitree Express Episode 1", a documentary by BBC.

Time and again the importance of multimedia has been stressed to bring in the real life experience to a taught work of art. It has been observed that the presentation of the cultural and social ethos visually can enhance the engagement of a learner with a narrative. The Shadow Lines (1988), which as a memory novel, sketches a few historical events like the freedom movement in Bengal, the Second World war, the Partition of India in 1947 and the communal riots in Bangladesh and India, consists of two parts, Going Away and Coming Back. It is a narrative of nostalgia, longing and liminality in a complete sense, where people's stories take over the nation's, worlds mingling in memories without a thought given to one's nationality.

'Amitav Ghosh problematizes nationalism in his search for identity through this novel. The fervent nationalism upheld by characters like thamma is put to question and re-analysis.' [5]. The shadowiness of the border line puts a question mark to the geographic boundary line between countries / nations and thus its identity. Ghosh considers space / place as non neutral, non objective. To him 'a place does not merely exist ............ It has to be invented in one's imaginations' [2].

\section{The Documentary: Maitree Express}

As the documentary opens with an echo of "baul song-a Bengali folk style of singing", [6] one is transported to the pre-independence Bengal. Baul geeti symbolically unifies and speaks for a unified culture. One may divide a nation politically but not culture. The song set in the abondonement of the vastness of Bengal in the background sets the platform to talk about the unified Bengal because the same genre of songs are heard in the homes of Dhaka and Calcutta, similar music resonates in cities and villages, and the same poetic works find their place in the shelves. The citizens of these nations identify themselves as Bengalis first, as Urmi-the passenger in the documentary reiterates, that first she is a Bengali and then a Bangladeshi.

"Through its 5000 yrs. of history the Indian sub-continent has suffered numerous invasions, the last was the British." [6] As the narrator opens the documentary with this sentence, one is eagerly looking for more. "They quit India in 1947 and hurriedly partitioned the sub-continent", [6] the voice booms over. As the movie progresses we are introduced to real life characters who have lived during the partition and the division of Bengal. The presentation of the documentary can bring forth the fact that the physical or political borders are but painful traumatic and cumbersome for people on both sides. Urmi Rehman who longs for her home but stays in Kolkata for example refused to give up her Bangladeshi passport.

\section{The Novel:}

The Shadow Lines In the same vein, The Shadow Lines is about partition wherein Ghosh questions the existence of borders through numerous symbolic suggestions and characters like 'thamma'. Urmi and thamma 
are the two characters in two separate eras but they virtually voice the concern of every being who's been subjected to the trauma of separation.

"Ghosh problematises nationalism in his search for identity". [3] The Shadow Lines questions the existence of political borders. Many a time they are clashing against one's personal reality and truth. The fact that Jethamosai, thamma's uncle, refuses to leave Dhaka and migrate to India endorses this sort of thinking. To quote Jethamosai, "I don't believe in this India -Shindia. It's all very well, you're going away now, but suppose when you set there they decide to draw another line somewhere? What will you do then? Where will you move to? No one will ever have you anywhere." (237) Relating to such heart wrenching and traumatic experiences could be more meaningful, when juxtaposed against a something film or a documentary.

\section{Analysis:}

The generation today is known to learn more through movies, animation and documentaries than books. Under such circumstances the question is how to sensitise them about the aesthetics of nation building? How to inform them about the past correctly, convey the correct version of history! Such questions find an answer in simulating a quasi-environment through virtual reality and media. It's a big social responsibility of the academicians to generate media resources that facilitate learning. One could observe the difference in the level of interest and engagement when such facilities are used.

Movies could be extremely helpful in understanding the stories beyond nation. Many historical movies and documentaries have always been a part of storytelling. Maitree is an observation and analysis of people's feeling after the partition of India. It's been 67 years now since we became a separate nation but the nostalgia remains. This can be specially seen in the sujourns and journeys of Bengali people whose emotions culminate into establishing a bridge between their previous and present lives. Whenever people travel from one part of Bengal to the other they seem to be visiting their memories their childhood and fond associations; as is vivid in the documentary. The whole story is about the train and the people who travel in it regularly, as if nothing has changed. The journey symbolises the connection that is never going to die; that lives in the emotions of people and is independent of borders. It's about people and their feelings and to allay their misery about the lost land, because the lost land is also the lost home and the lost social set up. The documentary is a step forward to reestablish this connect.

\section{A Comparison of Characters in the Novel to those in the Documentary:}

Ghosh explores the unreality and invalidity of traditional identity constructions such as nation and nationalism in the novel and the same is concretised by the characters in the documentary. Abdullah who earns some extra money by selling newspaper on Maitree Express has a story no different than any other local boy in Mumbai or Kolkata. Many diasporic writers have woven their novels very intricately around historical events like partition, especially Ghosh. His novels are metafictional in character and therefore require immense correlation to historical facts. What can be better than eliciting the same from the victims of the historical aftermaths who still are trying to locate their identitites and adjust to the ideosyncracies of national histories; the echo of baul with cargo and passenger boats drifting on the river Jomuna, simulates a sensation of longing and loss amongst those who are a part of the real world and not fictional characters in any novel. For example in the novel The Shadow Lines 'thamma' is perplexed when told that she needs a passport to travel to Dhaka; a city that has always been her home. The emotion entails itself in an interview with one of the passengers, in the train, who has been instrumental in liberating Bangladesh from Pakistan- Mr. Amrul, the public announcer of the Maitree Express.

"Technology does not necessarily drive education. That role belongs to the learning needs of students. With multimedia, the process of learning can become more goal oriented, more participative, flexible in time and 
space, unaffected by distance and tailored to individual learning style, and increase collaboration between teachers and students." [2] The aspects of culture in various dimensions can be viewed and felt when one uses media. In the student-centered method, the students construct their own knowledge and bring authentic experiences into the learning process with the teacher as the facilitator. 'With multimedia, the communication of the information can be done in more effective manner and it can be an effective instructional medium for delivering educational information because it enables the teacher to present the information in a kaleidoscopic manner.' [8]

In the same way the story tellers in the documentary, have their own dilemmas to share. In Supriya Chaudhuri's opinion 'In fiction you have set moving in the narrative, the existential dilemmas of people you are interested in.' [7] The documentary in its description of lives of people on board, validates all the claims that the narrative The Shadow Lines is making. Although media cannot bring home the exact but it brings in the almost exact.

\section{An analysis of comments by Supriya Chaudhari in context of History and Historiography:}

'While history makes claim to truth, fiction makes a claim to give us a version of the real, the facts are connected by a chain of causality which derives meaning by adding context to it.' [7]The above reflection by Supriya Chaudhari, brings out that the historical fiction performs the act of empathy of entering the minds of its protagonist and therefore it is essential to marry history and fiction. Media plays a very important role to validate the sense of historical wonder and outrage that a historical narrative creates. A narrative taught in the backdrop of a real life documentary can render the emotions genuinely and increase the depth of experience.

The documentary, 'Maitree Express Episode 1'- tells the tales of various characters, and in turn tries to overcome the vacuum and recover the story of the lost and neglected voices that never featured in any of the history books. As Mukul Kesavan an eminent historicist from India, rightly says 'To read about the past and to inhabit the past as well', [7] happens when one finds the right evidence to complete the experience. There is so much that has not been said about these lost subaltern voices, like thamma or Tridib. In 1964 when 'thamma' plans to visit Dhaka, she wonders whether she would be able to see the borders between India and East Pakistan from the aeroplane. When her grandson (the narrator) mocks her asking - if the border line was a long black line, she says, "of course not. But surely there's something - trenches perhaps, or soldiers or guns pointing at each other, or even just barren strip of land. Don't they call it no-man's land?"(167). As borders to Thamma are absolute physical \& tangible realistic entities, the absence of their sight confuses her as she wonders about the official processes she had to go through for her passport. Amitav Ghosh satirises the fact that such political identities try to define all individuals enmasse and actually are very poor representatives of people's emotions.

'Ghosh focuses on another very relevant aspect - that is - the history of the nation shallows up the story of the individual: In the riots of 1964, the narrator's uncle Tridib had lost his life as a helpless victim to the maddening frenzy of communal hatred. This was a key moment in the story of the narrator's life. But, when after fifteen years later in 1979, the narrator attempts to recover the traces of this event in the archives of the Nehru Memorial Library, New Delhi, he does not find any mention of Tridib's death in the newspapers. 'It seemed as if private story was not at all important for the nation's memory.' [5].

On the other hand Urmi Rehman, draped in a sari and donning a bindi, in the documentary does not believe that any border can cut her off from her erstwhile homeland or culture. She travels to Dhaka, the place of her birth and upbringing very often and maintains her friendships in the same way as before. The depiction of different communities coming together during Eid probably shows that narratives of human beings their personal relationships and interests may not always identify with the political. The contrast of voices and opinions have nothing to do with the politics of borders. 


\section{Conclusion}

The multimedia courseware content offers the flexibility to ponder and reflect in one's own space and time. Fictional narratives attain eternity when a connect is established between the present and the past. Historical metafictions are a beautiful way of telling the tales of the obscured people, the vacuum that the subaltern histories are a part of, is being erased by creation of a new archive, new databases and the truth of this can be packaged as a web file and delivered on the internet in a web browser. 'The students are then free to engage in learning on their own time and space, and consequently, the learning mode is student-centered.' [8] In a nutshell, multimedia can and has become a vital instrument in the modern day teaching learning processes and can especially be used to teach literature by increasing the realised sensation and experience multifolds.

$\mathrm{t}($ Author, 2018)

\section{References}

[1] Saxena Manjula, The Shadow Lines as a Memory Novel, in Arvind Chowdhary (Ed) Amitav Ghosh,s The Shadow Lines- Critical Essays (New Delhi: Atlantic publishers \& distributors(p) Ltd, 2008) .

[2] Das Sukanta, Beyond the frontiers: Quest for identity in Amitav Ghosh ${ }^{\text {ee }}$ The Shadow Lines, in The Atlantic Critical Review Quarterly. Vol-8 No-1, Jan - March, 2009.

[3]Sati Someswar - Interrogating the nation, Growing global in The Shadow Lines in Arvind Chowdhary (Ed) Amitav Ghosh's The Shadow Lines- Critical Essays (New Delhi: Atlantic publishers \& distributors(p) Ltd, 2008)

[4] Ghosh Amitav, The Shadow Lines, (Ravi Dayal Publisher \& Penguin Books, 2009)

(All subsequent textual references presented within brackets are to this edition)

[5] (PDF) Amitav Ghosh's "The Shadow Lines": Problematics of National Identity. Available from: https://www.researchgate.net/publication/270831934_Amitav_Ghosh's_The_Shadow_Lines_Problematics_of_ National_Identity

[6] BBC documentary India’s Frontier Railways, Maitree Express Episode 1

https://www.youtube.com/watch?v=i8hs24tvR_8

[7] A Talk by Amitav Ghosh, Mukul Kesavan, Supriya Chaudhuri at Tata Steel Kolkata Literary Meet 2016 https://www.youtube.com/watch?v=B27dz1pkvH0 